\title{
Imbalance in Life Table: Effect of Infant Mortality on Lower Life Expectancy at Birth
}

\author{
A. M. Fazle Rabbi* \\ Department of Applied Science, Bangladesh University of Textiles, Dhaka, Bangladesh \\ Received 9 March 2013, accepted in final revised form 12 May 2013
}

\begin{abstract}
Life expectancy at birth is a well-known demographic measure of population longevity. Rationally, life expectancy at birth should be higher than life expectancy at any particular age. However, historically, lower life expectancy at birth is observed than that of age one, which diminishes the feature of life expectancy at birth as a prominent indicator of longevity. High infant and child mortality rates result in lower values of life expectancy at birth than at older ages. This imbalance in life table disappears only when the crossover occurs and it happens when the inverse of the infant mortality becomes equal to the life expectancy at age one. For Matlab Health and Demographic surveillance system of Bangladesh, life expectancy at age one is still higher than life expectancy at birth. Required infant mortality rate to achieve crossover suggests further decline in infant mortality for Matlab HDSS to attain crossover of life expectancy at birth and age one.
\end{abstract}

Keywords: Life expectancies; Developing countries; Imbalance; Life table.

๑) 2013 JSR Publications. ISSN: 2070-0237 (Print); 2070-0245 (Online). All rights reserved. doi: http://dx.doi.org/10.3329/jsr.v5i3.14105 J. Sci. Res. 5 (3), 479-488 (2013)

\section{Introduction}

Life table is a nice mathematical tool to describe age-specific mortality, survival rates of a population and also the remaining expected life at a certain age. Period life expectancy at birth is defined as the average number of years that a newborn may live given a set of mortality rates seen in a calendar year [1]. The first of these averages (symbolized as $e_{0}$ ), is known as life expectancy at birth. It is a widely used summary indicator to describe population health along with longevity. For developed countries and industrialized countries, the $e_{0}$ calculated from period life tables is currently higher than the life expectancy at any other age, and the course of life expectancy by age decreases monotonically in next age groups [2].

However, dissimilarities have been observed for most of the under developed and developing countries. In historical populations as well as in many developing countries

*Corresponding author: amfrabbi@ hotmail.com 
life expectancy at birth has been found to be lower than other ages, sometimes up to age five years. Even industrialized countries faced this situation before a certain era [3]. High infant and early childhood mortality result in lower values of life expectancy at birth than at other ages [4]. It is observed that in such populations, those surviving the hazards of early childhood have a higher life expectancy than infants and the maximum life expectancy occurs not at birth but at a later age. This imbalance in life table usually disappears at higher age, which was expected to be at age one. Thus, changes in mortality in the first year of life significantly affect life expectancy at birth, and it has been recommended that the time series of $e_{0}$ alone is not well suited for studying the length of life in aging populations [5].

Few studies discussed about the differentials of infant mortality and life expectancies at birth; gender was found to be common significant differential for life expectancies [4]. Gender differences in infant mortality is responsible behind this sort of trend in life expectancies; the differentials and trends of infant mortality is evaluated extensively in previous researches [6-8]. Regional variation is also seen in pattern and trend of life expectancies at birth and age one, epidemiological transition was found also as determinant of this trend in few places of the world [9]. Whatever the differentials are, life expectancy by age became a monotonic decreasing function with increasing age for the developed countries since the second half of the twentieth century. It is not historical, considerable gaps between the life expectancy at birth and age one can be found in other countries, too [3].

Several studies have been done for historical data of the industrialized countries, minority and various special sub populations. Imbalance in life table can still be observed in black population in USA; black-white life expectancy gap is noteworthy also [10]. However, less illustration is observed for developing or under-developed countries. Incomplete data, lack of vital registration system is one of the major reasons behind this [2]. The United Nations (UN) and the World Health Organization (WHO) compute life tables and mortality estimates annually for all country members of UN; they also face the difficulties of incomplete dataset, as majority of the countries of the world have vital registration system (partial counts of vital events and/or populations). For those countries, life tables have to be constructed using a combination of direct and indirect methods [1112]. As estimation procedures are not identical for each organization, these estimates coming from UN and WHO for any given country do not always coincide [3]. Hence, imposing common assumptions for projecting desired infant mortality rates for life expectancies at various ages is unattainable in current conditions.

Therefore, the current study has major endeavor to relate infant mortality with life expectancy at birth. Previous research established relation on the basis of certain assumptions on radix and for continuous age, which is not suitable for conventional period life table; this study attempts to fill the gap by considering discrete age variable and without radix restriction [2]. These sorts of derived mathematical relations of the life table will allow researcher and population experts to find the precise relation between life expectancy at birth, age zero and infant mortality at the crossing in life expectancies. 
Also, required infant mortality rate to attain crossover in life expectancies at birth and age one is estimated using data of a demographic surveillance system from a developing country like Bangladesh.

\section{Data and Methodology}

As one of the aspects of current study is to focus the life expectancies from a developing country, Bangladesh is considered for illustration of the methodology in current study. Bangladesh, a developing country of South Asia, has not started complete vital registration system till now. The vital registration and maternal and child health data gathered from Matlab, Bangladesh [13] is utilized here. Since 1966, the Health and Demographic Surveillance System (HDSS) has maintained the registration of births, deaths, and migrations, in addition to carrying out periodical censuses in Matlab. Matlab HDSS is recognized worldwide as one of the long-term demographic surveillance sites in a developing country. There are two parts in the surveillance area - an ICDDR,B service area and Government service area which receives usual government health and family planning services. ICDDR,B service area is sub-divided into four blocks, where family planning, immunization and limited curative services are provided to under-five children and women of reproductive age. In 2010, the midyear population of ICDDR,B service area was 115652, of which 53866 were male and 61786 were female. Bangladesh became independent in 1971, so the life tables of 1975 to 2010 are considered for current study. The illustration is done all over the paper considering life tables separately for male and female, which enables the comparison between life expectancy and infant mortality pattern of both sexes, too. It should be noted that, only period life tables are used in current analysis, cohort life tables may produce different results than this.
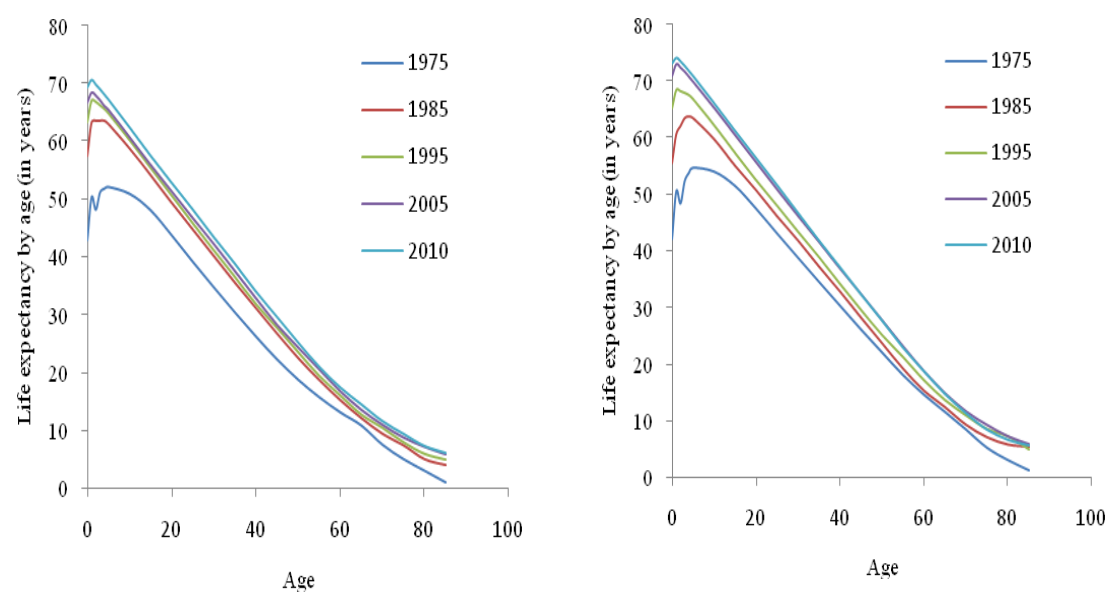

Fig. 1. Trend of Life expectancies at different ages for (a) male (left) and (b) female (right) (Matlab HDSS 1975-2010 [13]). 
Fig. $1(\mathrm{a}, \mathrm{b})$ represents life expectancy by age at different times for the population of the Matlab HDSS. In 1975, crossover of life expectancy at birth and other ages occurred after age 15 for male and 20 for female. Infant mortality rates were too high at that time for both sexes, which decreased over time. By the end of 2010, the crossover is occurring after age 2 (for both sexes). Hopefully, very soon these substantial gaps between the life expectancy at birth and life expectancy at age one will diminish to null for Matlab HDSS (details are discussed in Result section).

Generally, abridged life tables are constructed using the following mathematical relationships:

The number of survivors in a particular age $x$ is $l_{x}$ and number of deaths in an interval $x+n$ is, ${ }_{n} d_{x}=l_{x}-l_{x+n}$. At age 0 , the value of $l_{x}$ is known as radix and it is considered 100000 as a standard. Probability of surviving in particular age $x$ to $x+n$ is, ${ }_{n} p_{x}$ and death is ${ }_{n} q_{x}$ where, ${ }_{n} p_{x}=1-{ }_{n} q_{x}$ and, ${ }_{n} q_{x}=\frac{{ }_{n} d_{x}}{l_{x}}$. Thus, in a time interval $n, l_{x+n}=l_{x} p_{x}$ and ${ }_{n} d_{x}$ $=l_{x}{ }_{n} q_{x}$. The number of person-year lived by the cohort is, ${ }_{n} L_{x}=\int_{0}^{n} l_{(x+t)} d t$; which is equivalent to, ${ }_{n} L_{x}=\frac{n\left(l_{x}+l_{x+n}\right)}{2} ;(x \geq 2)$. For $x<2 ; L_{0}=0.201 l_{0}+0.8 l_{l}$ and, $L_{l}=0.410 l_{1}+$ $0.590 l_{2}[13]$.

Central death rate is defined as ${ }_{n} m_{x}={ }_{n} d_{x} /{ }_{n} L_{x}$. Also, $m_{x}=\frac{2 q_{x}}{2-q_{x}}$. The number of person-year lived by the life table population is, $T_{x}=\int_{0}^{\infty} L_{(x+t)} d t$; which is equivalent to $T_{x}=\sum_{t=0}^{\infty} L_{(x+t)}$.

Expectancy of life at age $x$ is, $e_{x}=\frac{T_{x}}{l_{x}}$.

\section{Derivation for crossover principle at age 1:}

For highest attainable age $w$, the life expectancy at birth is,

$$
e_{0}=\frac{L_{0}+L_{1}+\ldots .+L_{w}}{l_{0}}
$$

And in age 1,

$$
\begin{aligned}
& e_{1}=\frac{L_{1}+L_{2}+\ldots .+L_{w}}{l_{1}} \\
& \text { Or, } e_{1} l_{1}=L_{1}+L_{2}+\ldots . .+L_{w}
\end{aligned}
$$

From (1) and (2),

$$
e_{0}=\frac{e_{1} l_{1}+L_{0}}{l_{0}}=\frac{L_{0}+e_{1}\left(l_{0}-d_{0}\right)}{l_{0}}=e_{1}\left(1-q_{0}\right)+\frac{L_{0}}{l_{0}}=e_{1} p_{1}+\frac{L_{0}}{l_{0}}
$$


If crossover of life expectancies occurs at age 1 (for birth and age 1), then $e_{0}$ and $e_{1}$ will be equal. Replacing all $e_{0}$ by $e_{1}$ in (3), we have,

$$
e_{1}=\frac{L_{0}}{\left(1-p_{1}\right) l_{0}}=\frac{L_{0}}{q_{0} l_{0}}=\frac{L_{0}}{d_{0}}
$$

Using the definition of central death rate, ${ }_{n} m_{x}={ }_{n} d_{x} /{ }_{n} L_{x}$, we have,

$$
e_{1}=\frac{1}{{ }_{1} m_{0}}
$$

It should be noted that, Eq. (4) is obtained in a previous study [2] assuming $l_{0}=1$, to simplify equations. As the relations are same in both studies and are applied to same conventional life tables so the results will be same in both cases. Though radix is generally considered to be 100000 , Eq. (4) can be used without assumption of radix. Also, in the previous study this relation holds only for continuous age variable; Eq. (4) verified the relation for discrete age variable which is very common while dealing with conventional period life table [2].

\section{Relation between infant mortality and life expectancy at crossover}

For infant mortality,

$$
\frac{1}{e_{1}} \Leftrightarrow m_{0}=\frac{2 q_{0}}{2-q_{0}}=\frac{2 d_{0}}{2 l_{0}-d_{0}}
$$

which gives,

$$
d_{\mathrm{o}}=\frac{2 l_{\mathrm{o}}}{1+2 e_{1}}
$$

For various values of $e_{1}$ the required number of infant death for crossover can be calculated from (5), imposing the value of radix. It should be noted that, the term $e_{0}$ and $e_{1}$ can be used interchangeably in Eqs. (4) and (5), as the value of $e_{0}$ and $e_{1}$ are the same at crossover.

\section{Required IMR for crossover for particular life expectancy at birth}

As mid-year population size is available, mortality rates of Matlab HDSS is obtained using Greville's method [14]. The infant mortality rate (IMR) is defined as,

$$
I M R=\frac{m_{0}}{1+m_{0}\left[0.5+1 / 12+\left(m_{0}-0.095\right)\right]}
$$


Using Eq. (4), the optimal IMR for life expectancy at birth $\left(e_{0}\right)$ should be,

$$
I M R=\frac{1 / e_{0}}{1+1 / e_{0}\left[0.5+1 / 12+\left(1 / e_{0}-0.095\right)\right]}
$$

\section{Results}

The overall scenario of life expectancy at birth and age one in Matlab HDSS is summarized in Table 1. At the beginning of the HDSS, the infant mortality was high in case of female. But within decades, the scenario changed and by late 2010, it turns to be almost same.

Table 1 . Trend of life expectancy at birth $\left(e_{0}\right)$ and age one $\left(e_{1}\right),{ }_{1} m_{0}$ and infant mortality rate by sex (Matlab HDSS 1975-2010).

\begin{tabular}{cccccc|ccccc}
\hline Year & \multicolumn{5}{c}{ Male } & \multicolumn{5}{c}{ Female } \\
& $e_{0}$ & $e_{1}$ & $e_{0}-e_{1}$ & ${ }_{1} m_{0}$ & $I M R$ & $e_{0}$ & $e_{1}$ & $e_{0}-e_{1}$ & ${ }_{1} m_{0}$ & $I M R$ \\
\hline 1975 & 42.94 & 50.37 & -7.43 & 0.17991 & 165.06 & 42.08 & 50.51 & -8.43 & 0.20275 & 184.09 \\
1980 & 58.9 & 63.7 & -4.8 & 0.09446 & 90.2 & 54.1 & 60.3 & -6.2 & 0.12596 & 118.5 \\
1985 & 57.5 & 63.3 & -5.8 & 0.11299 & 86.0 & 55.6 & 60.7 & -5.1 & 0.10596 & 86.8 \\
1990 & 62.3 & 67.2 & -4.9 & 0.09134 & 87.3 & 64.3 & 68.6 & -4.3 & 0.07990 & 76.8 \\
1995 & 63.3 & 67.0 & -3.7 & 0.07217 & 90.8 & 65.2 & 68.4 & -3.2 & 0.06260 & 65.5 \\
2000 & 66.0 & 68.6 & -2.6 & 0.05364 & 52.2 & 69.1 & 71.8 & -2.7 & 0.05227 & 50.9 \\
2005 & 66.8 & 68.5 & -1.7 & 0.03965 & 38.9 & 70.8 & 72.9 & -2.1 & 0.04312 & 42.2 \\
2010 & 69.3 & 70.6 & -1.3 & 0.03345 & 32.9 & 73.2 & 74.2 & -1.0 & 0.02759 & 27.2 \\
\hline
\end{tabular}

The difference between $e_{0}$ and $e_{1}$ declined with decrease in infant mortality. At the earlier era of HDSS, the IMR was more than 100 births per thousand while by late 2010 it clustered near 30 (for both sexes). The difference between $e_{0}$ and $e_{1}$ is still over 1 , which should be zero to achieve crossover. The possible timing and required $I M R$ for crossover are calculated later in this section. The least difference in $e_{0}$ and $e_{1}$ is observed for female; also the life expectancy at birth is higher for female. Similar situation was observed for countries which attain the crossover $[2,19]$. This difference in life expectancies turned to zero when Eq. (4) is fulfilled. Initially these differences remain negative, but move to positive values after the life tables achieve a balanced situation [2]. Comparing in terms of $I M R$, females are in a higher position than male. Inverse of ${ }_{1} m_{0}$ and $e_{0}, e_{1}$ are shown in Figs, 2(a) and 2(b), respectively. 

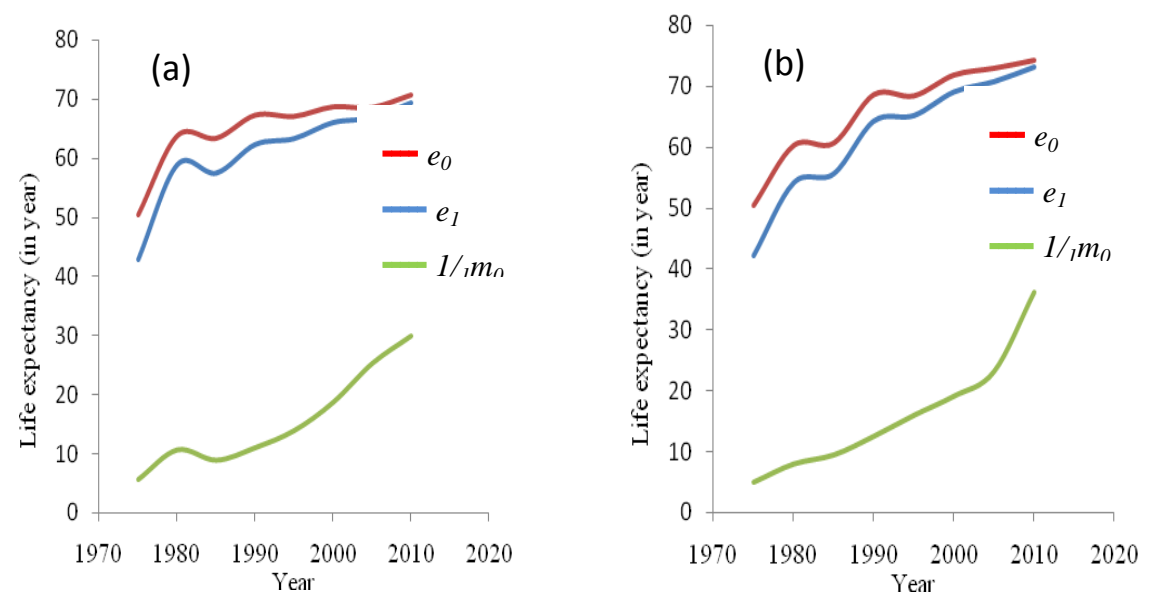

Fig. 2. Life expectancies at birth $\left(e_{0}\right)$, age one $\left(e_{1}\right)$ and the inverse of infant mortality $\left(1 /{ }_{1} m_{0}\right)$ for (a) male (left) and (b) female (right) (Matlab HDSS 1975-2010).

For both sexes, the lines of $e_{0}$ and $e_{1}$ seem to be close enough to intersect within the next few years. But still the inverse of infant mortality is far away from the lines of $e_{0}$ and $e_{1}$. Since the value of ${ }_{1} m_{0}$ are close to zero; little change in the value of ${ }_{1} m_{0}$ will affect the inverse of ${ }_{1} m_{0}$ in a significant amount in future. The observed mortality rate for female was 0.02759 in 2010 , which has an inverse of 36.245 years; this is still too far away from life expectancy at birth for female (74.2 years). From the lines of inverse of ${ }_{l} m_{0}$, the lines seem to have a rapid increase in the recent years for females; males seem to have an almost secular trend. According to Eq. (4), the crossover of life expectancy at age zero and one occur only when the three lines coincide with each other. If the current trend continues in Matlab HDSS, hopefully the crossover will occur in near future.

It can be seen for most of the developed and industrialized countries that the crossover occurs for more than one time before the stabilization of life table. This is due to fluctuation in infant mortality rate [15-18]. Similar pattern may also be observed in Matlab HDSS in last decades; IMR fluctuated for several times, which is also reflected in the difference of $e_{0}$ and $e_{1}$. That is why instead of forecasting the possible time of crossover, the least level of IMR to achieve crossover at life expectancy at birth and age one are estimated in the present study. Table 2 shows the estimated least level of $I M R$ for particular life expectancy at birth. Most of the countries, which attain the crossover, have life expectancy at birth less than 80 years at the time of crossover [2]. As the last observed life expectancy at birth was seen to be 69.3 years, the estimation of the required IMR remained close to 69.3 to 85.3 years only. Comparing Table 2 with Table 1, it is seen that $I M R$ of Matlab HDSS is too high to achieve crossover. To satisfy the relation obtained in Eq. (4), more decrease in IMR is required for Matlab HDSS. 
Table 2. Required infant mortality rate for various life expectancy at birth for crossover (estimation based on Eq. 6).

\begin{tabular}{cccccc}
\hline $\begin{array}{c}\text { Life } \\
\text { expectancy } \\
\text { at birth }\end{array}$ & $\begin{array}{c}\text { Required } \\
\text { IMR for } \\
\text { crossover }\end{array}$ & $\begin{array}{c}\text { Life } \\
\text { expectancy } \\
\text { at birth }\end{array}$ & $\begin{array}{c}\text { Required } I M R \\
\text { for crossover }\end{array}$ & $\begin{array}{c}\text { Life } \\
\text { expectancy } \\
\text { at birth }\end{array}$ & $\begin{array}{c}\text { Required } I M R \\
\text { for crossover }\end{array}$ \\
\hline 69.3 & 14.32608 & 74.4 & 13.35082 & 79.5 & 12.49986 \\
69.6 & 14.26479 & 74.7 & 13.29757 & 79.8 & 12.45317 \\
69.9 & 14.20401 & 75.0 & 13.24474 & 80.1 & 12.25480 \\
70.2 & 14.14376 & 75.3 & 13.19233 & 80.4 & 12.36082 \\
70.5 & 14.08401 & 75.6 & 13.14033 & 80.7 & 12.31516 \\
70.8 & 14.02476 & 75.9 & 13.08875 & 81.0 & 12.26984 \\
71.1 & 13.96601 & 76.2 & 13.03756 & 82.3 & 12.07722 \\
71.4 & 13.90775 & 76.5 & 12.98678 & 82.6 & 12.03363 \\
71.7 & 13.84998 & 76.8 & 12.93638 & 82.9 & 11.99035 \\
72.0 & 13.79268 & 77.1 & 12.88638 & 83.2 & 11.94738 \\
72.3 & 13.73586 & 77.4 & 12.83676 & 83.5 & 11.90472 \\
72.6 & 13.67950 & 77.7 & 12.78753 & 83.8 & 11.86236 \\
72.9 & 13.62360 & 78.0 & 12.73867 & 84.1 & 11.82030 \\
73.2 & 13.56815 & 78.3 & 12.69018 & 84.4 & 11.77854 \\
73.5 & 13.51316 & 78.6 & 12.64206 & 84.7 & 11.73707 \\
73.8 & 13.45861 & 78.9 & 12.59430 & 85.0 & 11.69589 \\
74.1 & 13.40450 & 79.2 & 12.54690 & 85.3 & 11.65500 \\
\hline
\end{tabular}

\section{Discussion}

One of the characteristics of demographic transition is increase in life expectancy at birth. Throughout this transition, imbalanced life tables have been observed for developing countries. For developed countries, life expectancy by age became a monotonic decreasing function with increasing age in the second half of the twentieth century. However, in the past this was not the case $[2,19]$. This imbalance will discontinue only when the life expectancy at birth and age one will be equal to each other, i.e. for $e_{0}=e_{1}$. The major concern of the current paper is to derive optimal condition for crossover of life expectancy at birth and age one and to illustrate it using data of a developing country. Previous research established relation on the basis of certain assumptions on radix and for continuous age, which is not suitable for conventional period life table where discrete age are considered (in year). This study attempts to fill the gap by considering discrete age variable and without radix restriction [2]. Thus, the relation re-established in current study is much more suitable for conventional period life table.

There are two parts of the current study. Towards the methodology; the optimal situation when the crossover will occur is derived along with relation of optimal number 
of deaths for achieving the crossover. The estimation was done before but under certain assumptions. In this study the relation is re-established without any assumptions [2]. As the relations are same and are applied to same conventional life tables, the results will be same in both the cases. Though radix is generally considered to be 100000, the derived Eq. (4) can be used without assumption of radix. Also, in previous study this relation holds only for continuous age variable, but in the present paper the relation is verified for discrete age variable which is very common while dealing with conventional period life table [2]. The crossover of life expectancy at birth and age one will occur only when the life expectancy at birth will be equal to the inverse of infant mortality. Next, the derived methods are illustrated using the data of Matlab Health and Demographic Surveillance System for the period 1975 to 2010 in the present study.

Despite notable increase in life expectancy in the last decades, the importance of study of determinants and pattern of infant mortality still carry weights [18, 20]. Due to presence of moderately high infant mortality rate, a difference exists between life expectancy at birth and age one for Matlab HDSS. The lowest difference in $e_{0}$ and $e_{1}$ is observed for female along with least infant mortality rate, though the line indicating inverse of infant mortality is still far away from lines of $e_{0}$ and $e_{1}$. This is a must for crossover (inverse of infant mortality is 36.425 years while life expectancy at birth was 74.2 years). Like the previous studies, the data of Matlab HDSS also showed the differential nature of gender in terms of life expectancy for all of the age groups $[18,21]$. At earlier era of HDSS, female life expectancies were lower compared to those of the male. But in recent years females have higher life expectancies and lower infant mortality compared to those of the male. This is an outstanding outcome for the surveillance area for a developing country.

From the derived equations and findings from Matlab HDSS (1975-2010), the effect of infant mortality is reflected on life table. Extensive researches have been done on trend and differentials of infant mortality, though the current study focused only on the sexdifferential. The illustration of the crossover in life expectancy observed in previous study suggests that socio-cultural, economic, and political factors that persuade the intermediate factors shaping the mortality patterns in each country have passed through international borders [2]. Like many other developing countries, the lack of vital registration system limits the range of current analysis. On the basis of findings from the current study, the regional variation in life expectancies can be verified in future studies for Bangladesh. These sorts of comparison can be helpful to define separate clusters or sub population with different life expectancies, which will also be obliging to reduce infant mortality in different clusters.

It is hard to explain the overall mortality scenario of a country using only infant mortality rates. Another aspect of the current study is, life expectancy observed even after the crossover is not the same as the last age group attained by the life table cohort. The query on question like how much year a cohort can finally attain in a developing country may be another important point for further research [2]. Analysis from different countries from different regions suggests that alternative indexes at different ages offer the 
possibility of an internal comparison of levels of mortality in the population under study [3]. This is particularly important for not only Bangladesh, but also for other developing countries which are still experiencing an imbalanced life table and for studies of historical populations. Also, the mortality estimates used in this study can be used only under certain assumptions but not as a general one. Infant mortality rate computed from any customary method $[12,22]$ may show different relation with life expectancy. Finally, instead of using period life tables, cohort life tables may produce different results than that of current study.

\section{Reference}

1. S. H. Preston, P. Heuveline, and M. Guillot, Demography: Measuring and Modeling Population Processes, $1^{\text {st }}$ Edition (Blackwell, Malden-MA, 2001).

2. V. C. Romo, and S. Becker, Demographic Research 24 (4), 113 (2011). http://dx.doi.org/10.4054/DemRes.2011.24.4

3. V. C. Romo, and M. Engelman, Genus 65 (1), 59 (2009).

4. J. Oeppen, and J. W. Vaupel, Science 296 (5570), 1029 (2002). http://dx.doi.org/10.1126/science. 1069675

5. V. Kannisto, Popul. Engl. Sel. 13 (1), 159 (2001).

6. J. N. Hobcraft, J. W. McDonald, and S. O. Rutstein, Popul. Stud. 38 (2), 193 (1984).

7. J. G. Cleland, and J. K. V. Ginneken, Soc. Sci. Med. 27 (120), 1357 (1988). http://dx.doi.org/10.1016/0277-9536(88)90201-8

8. C. J. Murray, Int. J. Epidemiol. 17 (1), 122 (1998). http://dx.doi.org/10.1093/ije/17.1.122

9. A. R. Omran, Milbank Memorial Fund Quarterly 49 (4), 509 (1971). http://dx.doi.org/10.2307/3349375

10. S. Harper, J. Lynch, S. J. D. Burris, and G. D. Smith, J. Am. Med. Assoc. 297 (11), 1224 (2007). http://dx.doi.org/10.1001/jama.297.11.1224

11. United Nations, Model life tables for developing countries, (sales no. e.81.xiii.7) ed. (United Nations, New York, 1982).

12. C. L. J. Murray, B. D. Ferguson, A. D. Lopez, M. Guillot, A. J. Salomon, and O. Ahmad, Popul. Stud. 57 (2), 165 (2003). http://dx.doi.org/10.1080/0032472032000097083

13. ICDDR,B, Health and Demographic Surveillance System-Matlab, v. 44, Registration of health and demographic events 2010, Scientific Report No. 117 (ICDDR,B, Dhaka, 2012).

14. H. S. Shryock, J. S. Siegel, and D. A. Swanson, The Methods and Materials of Demography, U.S. Department of Commerce, Bureau of the Census (1975).

15. J. R. Wilmoth, and H. Lundstrom, Eur. J. Popul. 12, 63 (1996). http://dx.doi.org/10.1007/BF01797166

16. K. M. White, Popul. Dev. Rev. 28 (1), 59 (2002). http://dx.doi.org/10.1111/j.1728-4457.2002.00059.x

17. A. Kasmel, V. Helasoja, A. Lipand, R. Prättälä, J. Klumbiene, and I. Pudule, Eur. J. Publ. Health 2004, 14 (1), 32 (2004).

18. K. Fuse, and E. M. Crenshaw, Soc. Sci. Med. 62 (2), 360 (2006). http://dx.doi.org/10.1016/j.socscimed.2005.06.006

19. J. W. Vaupel, and V. C. Romo, Demographic Research 7 (1), 1 (2002). http://dx.doi.org/10.4054/DemRes.2002.7.1

20. O. Ahmad, A. D. Lopez, and M. Inoue, Bull. World Health Organ. 10 (78), 1175 (2000).

21. M. Leinsalu, D. Vågerö, and A. E. Kunst, J. Epidemiol. Community 58 (7), 583 (2004). http://dx.doi.org/10.1136/jech.2003.013755

22. W. Brass, On the scale of mortality, In: Brass, W. (ed.) Biological Aspects of Demography (Taylor \& Francis, London, 1971). 